0

\title{
Co-pyrolysis of biomass and plastic waste over zeolite- and sodium-based catalysts for
} enhanced yields of hydrocarbon products \section{Payam Ghorbannezhad*a, Sunkyu Park ${ }^{\text {b }}$, Jude A. Onwudili*c,}

${ }^{a}$ Department of Biorefinery Engineering, Faculty of New Technologies and Energy Engineering, Shahid Beheshti University, Zirab Campus, Mazandaran, Iran.

${ }^{\mathrm{b}}$ Department of Forest Biomaterials, College of Natural Resources, NC State University, NC 27695, USA.

${ }^{\mathrm{c}}$ European Bioenergy Research Institute, Chemical Engineering and Applied Chemistry, Aston University, Aston Triangle, B4 7ET, Birmingham, United Kingdom.

\section{Abstract}

Ex-situ co-pyrolysis of sugarcane bagasse pith and polyethylene terephthalate (PET) was investigated over zeolite-based catalysts using a tandem micro-reactor at an optimised temperature of $700{ }^{\circ} \mathrm{C}$. A combination of zeolite (HZSM-5) and sodium carbonate/gamma-alumina served as effective catalysts for $18 \%$ more oxygen removal than HZSM-5 alone. The combined catalysts led to improved yields of aromatic (8.7\%) and olefinic (6.9\%) compounds. Carbon yields of $20.3 \%$ total aromatics, $18.3 \%$ BTXE (benzene, toluene, xylenes and ethylbenzene), $17 \%$ olefins, and $7 \%$ phenols were achieved under optimal conditions of $700^{\circ} \mathrm{C}$, a pith (biomass) to PET ratio of 4 and an HZSM-5 to sodium carbonate/gamma-alumina ratio of 5. The catalytic presence of sodium prevented coke formation, which has been a major cause of deactivation of zeolite catalysts during co-pyrolysis of biomass and plastics. This finding indicates that the catalyst combination as well as biomass/plastic mixtures used in this work can lead to both high yields of valuable aromatic chemicals and potentially, extended catalyst life time.

Keywords: Sugarcane bagasse pith, polyethylene terephthalate (PET), co-pyrolysis, HZSM5/ $\mathrm{Na}_{2} \mathrm{CO}_{3} / \gamma-\mathrm{Al}_{2} \mathrm{O}_{3}$ catalysts, hydrocarbons 
27 (1) Email address: j.onwudili@aston.ac.uk; Tel: +44 (0) 1212044703

28 Postal Address: European Bioenergy Research Institute, Chemical Engineering and Applied

29 Chemistry, Aston University, Aston Triangle, B4 7ET, Birmingham, United Kingdom

30 (2) Email address: p_ghorbannezhad@ @bu.ac.ir; _Tel: +98-911-226-6745

31 Postal Address: Department of Biorefinery Engineering, Faculty of New Technologies and

32 Energy Engineering, Shahid Beheshti University, Zirab, Mazandaran, Iran.

33

34

35

36

37

38

39

40

41

42

43

44

45

46

47 


\section{Introduction}

49 The impending transition to a low-carbon economy appears immutable and it has been generally accepted that lignocellulosic biomass can play a pivotal role as a valuable renewable resource for

51 the production of biofuels, bio-based chemicals, and biomaterials. Unlike petroleum sources,

52 lignocellulosic biomass can be sustainably grown to be carbon-neutral, enabling mitigation of the

53 effects of greenhouse gases (GHG) emissions. Sugarcane bagasse is one of the most abundant

54 agricultural wastes, with approximately 570 million tonnes generated annually around the world

55 (FAOSTAT, 2018). In tropical and sub-tropical countries, sugarcane bagasse is used for pulp and

56 paper production. However, the presence of pith in the bagasse can cause operational problems

57 (Rainey and Covey, 2016). Sugar cane bagasse contains up to $30 \mathrm{wt} \%$ of pith, which is removed

58 during pulp and papermaking because of foaming, increased consumption of cooking chemicals

59 and as well as reduction in paper quality (Chambon et al., 2018). Therefore, the large amounts of

60 pith could be separated and deployed as an abundant and sustainable biomass feedstock for the

61 production of energy and chemicals.

62

63 Today, global production of plastics stands at nearly 300 million tonnes per year, a large proportion

64 of this being the so-called single-use plastics, which end up mostly as waste. In 2016 alone, Europe

65 generated more than 25 million tonnes of plastic waste, of which $39 \%$ was landfilled (Ratnasari et

66 al., 2017). Among plastic wastes, PET is seen as a problem plastic for thermochemical recyclers

67 because of benzoic acid generation as a major degradation product, which impacts the quality of

68 pyrolysis oil (Diaz-Silvarrey, et al. 2018). The global consumption of PET is nearly 16 million

69 tonnes per year and it is estimated to reach more than 20 million tonnes by 2020 (TCPIE, 2017).

70 Although PET is largely recyclable into fibers, bottles, amorphous PET (APET) sheets and 
71 strapping tape applications, the overall recycling rate of PET is still very low; for example it is less

72 than $10 \%$ in the USA (Ko, Sahajwala, and Rawal, 2014).

74 Therefore, plastic waste and agricultural wastes, such as pith of sugarcane bagasse, are abundant 75 sources for energy and chemical production, which otherwise pose serious disposal problems. The 76 fast pyrolysis is recognized as a more economical and environmentally friendly method to produce 77 biofuel and value-added products (Bridgwater, 2012). The condensed liquid product (bio-oil) can 78 be upgraded, mainly through the removal of oxygenated compounds in order to improve its fuel 79 and chemical properties (Bridgwater, 2012; Wang et al., 2015). Several physical, thermal, 80 chemical and catalytic technologies have been proposed for bio-oil upgrading but these are either 81 expensive or not widely available, and therefore have seen limited commercial interests 82 (Vanderbosch and Prins, 2010). In order to enhance the viability of bio-oil, researchers have 83 suggested co-pyrolysis of biomass and plastics as a potential route (Sharypov et al., 2002; Zhou et 84 al., 2006; Caglar and Aydinli, 2009; Brebu et al., 2010; Pinto et al., 2016). For example, biomass 85 can be co-processed via the catalytic co-pyrolysis with waste plastic using appropriate catalysts 86 (Dorado et al., 2015; Li et al., 2015; Jin et al., 2017; Chattopadhyay et al., 2018; Diaz-Silvarrey, 87 et al. 2018), to produce high-value aromatic (BTXE) chemicals, which are precursor compounds 88 in the pharmaceutical, textile, polymer, automobile, and food industries as well as important 89 additives for gasoline. The world demand for the aromatics including BTXE was valued at \$185.9 90 billion in 2017 (The Business Research Company, 2018). 
93 Catalytic fast pyrolysis (CFP) involves the direct conversion of pyrolysis vapours over a catalysts

94 bed without the need for vapour condensation and re-evaporation associated with conventional

95 bio-oil upgrading methods (Carlson et al., 2008; 2011; Cheng et al., 2011; 2012). CFP also avoids

96 the formation of difficult-to-process polymers during bio-oil condensation and storage (Wang, et

97 al., 2012; Elkabasi et al., 2014). Zeolite-based catalysts are effective for promoting the formation

98 of desired aromatic hydrocarbons during catalytic fast pyrolysis (CFP) of plastic-biomass blends

99 (Wang et al., 2013; 2014; Yao et al., 2015; Li et al., 2015). For instance, Zhang et al. (2015),

100 reported a relative content of $20 \%$ aromatics from the co-pyrolysis of biomass and plastics at a

101 temperature of $700{ }^{\circ} \mathrm{C}$. However, short catalyst life-time (Wang et al., 2013; 2014, low carbon

102 efficiencies (Yao et al., 2015) and formation of large amounts of char and coke (Yao et al., 2015;

103 Li et al., 2015) are serious technical drawbacks that preclude a cost-effective scale-up of CFP.

104 Recent research papers (Dorado et al., 2015; Li et al., 2015; Jin et al., 2017; Chattopadhyay et al., 105 2018; Lu et al., 2018) have revealed an enhancement of aromatic hydrocarbons yields when using

106 HZSM-5 catalysts during the pyrolysis of biomass with aliphatic polymers (PE and PP) and PET.

107 In general, literature has established the positive synergy between biomass and these plastics,

108 resulting in enhanced aromatic carbon yield and reduction of the solid residue (Dorado et al., 2015;

109 Lu et al., 2018). Due to the higher calorific values of plastics compared to biomass, catalytic fast

110 co-pyrolysis of the two feedstocks results in liquids with high energy density (Jin et al., 2017;

111 Chattopadhyay et al., 2018).

112 Although different studies have been conducted about co-pyrolysis of biomass and plastics over 113 zeolite catalysts, yet the short lifetime of the zeolite catalysts and the formation of coke during the 114 process remain a great challenge. In addition, the optimization of the catalytic biomass - plastic 115 co-pyrolysis process, e.g. with regard to the optimal biomass to catalyst ratio for high yields of 
116 aromatic and olefin compounds is not well understood yet. Thus, the overarching aim of this work

117 is the elucidation of the optimal reaction conditions to achieve high yields of aromatic

118 hydrocarbons compounds and low coke formation during the ex-situ catalytic fast co-pyrolysis of

119 PET and sugarcane bagasse pith using a novel combination of $\mathrm{Na}_{2} \mathrm{CO}_{3} / \gamma-\mathrm{Al}_{2} \mathrm{O}_{3}$ and HZSM-5

120 catalysts.

\section{2. Material and methods}

122

123

124

125

126

127

128

129

130

131

132

133

134

135

136

137

138

\section{$2.1 \mathrm{Na}_{2} \mathrm{CO}_{3} / \gamma-\mathrm{Al}_{2} \mathrm{O}_{3} / \mathrm{HZSM}-5$ catalysts}

$\mathrm{Na}_{2} \mathrm{CO}_{3} / \gamma-\mathrm{Al}_{2} \mathrm{O}_{3}$ catalyst and HZSM-5 catalyst $(\mathrm{Si} / \mathrm{Al}$ ratio $=23)$ were purchased from Zeolyst

(Netherlands). Before use, the catalysts were treated by calcination at a temperature of $600{ }^{\circ} \mathrm{C}$ in a muffle furnace for $5 \mathrm{~h}$. The calcined catalysts were then mixed in different ratios and crushed before sieving to $300-500$ microns particle size. Five catalysts with different HZSM-5: $\mathrm{Na}_{2} \mathrm{CO}_{3} / \gamma-$ $\mathrm{Al}_{2} \mathrm{O}_{3}$ ratios of $1: 1$ to $1: 5$ were prepared and used for the catalytic pyrolysis of the mixture of the biomass and PET samples.

\subsection{Characterisation of sugarcane bagasse pith}

The sugarcane bagasse pith used in this study was obtained from the southern part of Iran. It was initially pre-dried under sunlight for two days to decrease its moisture content below $10 \mathrm{wt} \%$. Thereafter, it was further dried in an oven at $105{ }^{\circ} \mathrm{C}$ for $2 \mathrm{~h}$. The material was subsequently comminuted to a size of less than $0.3 \mathrm{~mm}$ for analytical procedures. Proximate analysis (moisture, volatile matter, fixed carbon, and ash content) and ultimate analysis (carbon, hydrogen, nitrogen, and sulfur), were carried out on the bagasse pith to determine its composition. Proximate analysis was performed using a Perkin Elmer Pyris 1 thermogravimetric analyzer (Shelton, U.S.A). The carrier gas was $\mathrm{N}_{2}$ at a flow rate of $10 \mathrm{ml} / \mathrm{min}$. Separate samples of bagasse pith and PET were 
139 loaded into the thermo-balance and heated up from 32 to $105{ }^{\circ} \mathrm{C}$ at $25^{\circ} \mathrm{C} / \mathrm{min}$ after which they 140 were kept isothermal at $105^{\circ} \mathrm{C}$ for 5 minutes. Subsequently, each sample was heated up from 105 141 to $905^{\circ} \mathrm{C}$ at $25^{\circ} \mathrm{C} / \mathrm{min}$ and held at $905^{\circ} \mathrm{C}$ for 15 minutes, before cooling to $200{ }^{\circ} \mathrm{C}$ at $25^{\circ} \mathrm{C} / \mathrm{min}$. 142 Air was introduced at $20 \mathrm{ml} / \mathrm{min}$ and the sample reheated to $575^{\circ} \mathrm{C}$ at $100{ }^{\circ} \mathrm{C} / \mathrm{min}$ and $\mathrm{kept}$ at 575 $143{ }^{\circ} \mathrm{C}$ for 15 minutes to burn off any remaining char (Ghorbannezhad et al., 2018b).

144 An adjustment of the ASTM D5373 standard method was used to determine the elemental 145 composition (CHNSO), using an EXETER CE 490 elemental analyzer (ASTM, 2016). Using the 146 ASTM protocols, the ultimate analyses were also performed. Standard methods (TAPPI, 2018) 147 were used to characterise the pith sample for the contents of cellulose (TAPPI, T264 om-88), 148 hemicellulose (TAPPI, T223 om-88), lignin (TAPPI T222 om-88), and acetone or ethanol 149 extractables (TAPPI T 204 om-88).

\subsection{Hot water pre-treatment of sugarcane bagasse pith}

152 Due to the process of producing and obtaining sugarcane bagasse pith, it often contains inorganic 153 materials, which may affect the pyrolysis process and influence product yields (Teng et al., 1998; 154 Xue, Braden and Bai, 2017). To remove the inorganics, a hot water pre-treatment procedure was 155 performed, using a water/solid mass ratio of 20 (Ghorbannezhad et al., 2018a). The biomass-water 156 mixture was heated to a temperature of $90^{\circ} \mathrm{C}$ for $30 \mathrm{~min}$, after which the biomass was washed and 157 dried in an oven at $105^{\circ} \mathrm{C}$ for $5 \mathrm{~h}$ to decrease the moisture content below $10 \mathrm{wt} \%$. The washed 158 sample was subsequently comminuted using a $1 \mathrm{~mm}$ hammer mill and sieved to a particle size 159 between $0.25 \mathrm{~mm}$ and $1 \mathrm{~mm}$ and used for the thermogravimetric analysis and catalytic fast 160 pyrolysis experiments. The biochemical compositions of the pre-treated bagasse pith sample were: $16147.8 \%$ cellulose, $21.3 \%$ hemicellulose, $29.87 \%$ lignin and $1.12 \%$ extractives. 


\subsection{Ex-situ catalytic fast pyrolysis experiments}

163 Ex-situ catalytic fast co-pyrolysis experiments of biomass and PET were conducted in a tandem 164 micro-pyrolyzer system (Rx-300 TR, Frontier Laboratories, Japan). The schematic of the 165 experimental setup can be found elsewhere (Wang et al., 2015). Briefly, the system consisted of 166 two independently heated temperature-programmable micro-reactors interfaced to a GC split 167 injection port. One of the micro-reactors was used for pyrolysis while the other contained the 168 catalyst bed for post-pyrolysis reactions of the pyrolysates. For each test, microgram quantities of 169 the biomass/PET mixtures (at different mass ratios) were placed in an $80 \mu \mathrm{L}$ deactivated stainless 170 steel cup, which then dropped into the $1^{\text {st }}$ reactor for the pyrolysis process at set-point temperatures

171 from 400 to $800^{\circ} \mathrm{C}$. The pyrolysis vapours, was carried by helium flow directly over a fixed bed 172 of catalysts, located in the $2^{\text {nd }}$ downstream quartz-tube micro-reactor held at a fixed temperature 173 of $450{ }^{\circ} \mathrm{C}$. The catalyst bed temperature was selected based on some optimisation experiment using 174 three temperatures in the $400-800^{\circ} \mathrm{C}$ range (Ghorbannezhad et al., 2018b).

175

176 The vapour products leaving the second reactor were fed, via a dedicated interface, into a gas 177 chromatography fitted to a mass spectrometer (GC-MS) for separation and analysis. For the 178 analytical procedure, the injection port was held at $300{ }^{\circ} \mathrm{C}$ and the $\mathrm{GC}$ oven temperature was 179 initially held at $45^{\circ} \mathrm{C}$ for $3 \mathrm{~min}$, then ramped up to $280{ }^{\circ} \mathrm{C}$ with a heating rate of $10{ }^{\circ} \mathrm{C} / \mathrm{min}$, where 180 it stayed for an additional $6 \mathrm{~min}$, given a total analysis time of $32.5 \mathrm{~min}$. Helium, at a constant flow 181 of $1 \mathrm{ml} / \mathrm{min}$, was used as the carrier gas. A split ratio of 1:50 was used each time and all 182 measurements were performed, at least in duplicate to verify the reproducibility of the data. 183 Identification of components was carried out using the NIST10 Library Software installed on the 
184 GC-MS system, while quantification of the yields of identified was determined through calibration 185 with external standards.

186 Equation (1) was used to calculate the \% carbon molar yield of each compound identified and 187 quantified as follows:

$188 \%$ Molar carbon yield $=\frac{\text { Moles of carbon in products }}{\text { Moles of carbon in feedstock }} \times 100$

\subsection{Optimization by response surface methodology}

191 A central composite design (CCD) methodology was applied to identify and optimise the effects 192 of process conditions on the yield of valuable products. The co-pyrolysis temperature, biomass193 to-PET ratio, and $\mathrm{HZSM}-5$-to- $\gamma-\mathrm{Al}_{2} \mathrm{O}_{3} / \mathrm{Na}_{2} \mathrm{CO}_{3}$ catalysts ratio were the independent variables. The 194 total aromatics, BTXE, olefins, and phenols yields were set as the dependent variables. A least195 square multiple regression methodology was performed to analyze the data using the Design 196 Expert 7 software package (Ghorbannezhad et al., 2018b). The experimental design results were 197 fitted using Eq. 2:

$198 Y=\beta_{k 0}+\sum_{i=1}^{4} \beta_{k i} x_{i}+\sum_{i=1}^{4} \beta_{k i i} x_{i}^{2}+\sum_{i \mathrm{p} j=2}^{4} \beta_{k i j} x_{i} x_{j}$

$199 Y$ is the predicted response (product yields); $\beta_{k 0}, \beta_{k i}, \beta_{k i i}$ and $\beta_{k i j}$ represent regression 200 coefficients; and $x_{i} x_{j}$ are the coded independent factors (temperature, biomass to plastic ratio, 201 and $\mathrm{HZSM}-5$ to $\gamma-\mathrm{Na}_{2} \mathrm{CO}_{3}$ ratio).

202 The best model was selected based on the coefficient of determination $\left(\mathrm{R}^{2}\right)$, the adjusted coefficient 203 of determination $\left(\mathrm{R}^{2}\right.$-adj), the predicted coefficient of determination $\left(\mathrm{R}^{2}\right.$-pred), root mean square 204 error of the predictions (RMSEP, see Eq. 3), and the absolute average deviation (AAD). Preferably, 
$205 R^{2}$ must be near to 1 and the RMSEP and AAD (see Eq. 4) between the estimated and observed 206 data must be as low as possible (Myers, Montgomery, Anderson-Cook, 2011).

$207 \quad \mathrm{RMSEP}=\sqrt{\frac{\sum_{i=1}^{N}(\text { ypre-yexp }) 2}{N}}$

$208 \mathrm{ADD}=\left\{\sum_{\mathrm{i}=1}^{\mathrm{N}}(\mid\right.$ yexp - ypre $\mid /$ yexp $\left.) / N\right\} \times 100$

$209 Y_{\text {pre }}, Y_{\text {exp }}$, and $N$ are the predicted data, observed data, and the number of treatments, respectively.

210 The significant model of lack of fit indicates the equation of fitting is suitable to characterize the 211 results. All equations were obtained after elimination. After selecting the most accurate model, the 212 analysis of variance (ANOVA) was used to determine the statistical significance of the regression 213 coefficients by conducting a Fisher`s F-test at 95\% confidence level. The interactive effects of the 214 factors were observed using surface plots, derived from the chosen model (Ghorbannezhad et al., 215 2016). Finally, the process was optimized, with the aim of maximizing the aromatics, BTXE, 216 olefins, and phenols yields with the same weight $(\mathrm{w}=1)$ and the credibility of the optimum 217 conditions was diagnosed through the desirability values of the responses which ranged from 0 to 218 1. The closer values of desirability to 1 showed the more desirable and credible optimal conditions. 219 In this study, after the optimum point was obtained with the CCD software, the samples were tested 220 at this optimum point by laboratory experiments to obtain the results presented here. Furthermore, 221 these results were validated by a control experiment under the predicted optimum conditions.

223 3. Results and discussion

2243.1 Elemental analysis

225 The elemental compositions of bagasse pith and PET are presented in Table 1. One of the main 226 parameters for biomass characterisation is water content. The efficiency of the pyrolysis process 
227 is significantly reduced when moisture content is above $10 \mathrm{wt} \%$ (Bridgwater, 2012) and results in

228 Table 1 showed that the biomass was successfully dried to below $10 \mathrm{wt} \%$ moisture content prior

229 to pyrolysis in this work. The pith of sugarcane bagasse contained the high volatile matter (72

$230 \mathrm{wt} \%$ ) which indicated the capability of its devolatilisation. The characterisation of sugarcane

231 bagasse pith showed that it also contained substantial amounts of extractives and inorganic matter,

232 especially $\mathrm{Ca}, \mathrm{K}$, and $\mathrm{Mg}$ (Table 1). The inorganic compounds required attention due to their 233 catalytic activities, which could adversely affect the bio-oil yield and increase char formation 234 during the pyrolysis process (Xue, Braden and Bai, 2017). Thus, the pre-treatment of fresh pith 235 was essential to eliminate inorganic materials, without significant effects on the main biomass 236 components.

Table1. Ultimate and Proximate analysis of Pith of bagasse and PET

\begin{tabular}{c|c|c|c}
\hline Component & \multicolumn{2}{c}{ Weight\% } & $\begin{array}{c}\text { Standard } \\
\text { method }\end{array}$ \\
\hline \multicolumn{4}{c}{ Proximate Analysis (wt\%, db*) } \\
\hline Moisture & 10 & 0.5 & ASTM D 3173 \\
Volatile & 72 & 97.8 & ASTM 3174 \\
Fixed & 16.1 & 1.59 & ASTM 3175 \\
carbon & & & \\
Ash & 1.9 & 0.1 & ASTM 3172 \\
\hline \multicolumn{4}{c}{ Ultimate Analysis (wt\%, daf**) } \\
\hline C & 39.15 & 57.9 & ASTM D 4239 \\
H & 5.35 & 4.13 & ASTM D 4239 \\
N & 0.36 & 0.16 & ASTM D 4239 \\
S & 0.01 & 0.01 & ASTM D 4239 \\
O & 55.14 & 37.7 & By difference \\
\hline \multicolumn{4}{|c}{ Inorganic Compounds (ppm, db*) } \\
\hline Ca & 19110 & - & ASTM D 5373 \\
Mg & 3513 & 13.5 & ASTM D 5373 \\
K & 3139 & - & ASTM D 5373 \\
Al & 3596 & 217 & ASTM D 5373 \\
Si & 18350 & - & ASTM D 5373 \\
\hline \multicolumn{4}{|c}{$*$ dry basis; * daf = dry ash-free basis, } \\
\hline
\end{tabular}


240 Fig. 1 shows the TGA and DTG curves of the thermal and non-catalytic degradation of the 241 individual pith and PET samples at a heating rate of $20^{\circ} \mathrm{C} / \mathrm{min}$. For pith biomass, the first stage 242 started at room temperature and continued up to $100{ }^{\circ} \mathrm{C}$ with $10 \%$ weight loss, which is moisture 243 evaporation, followed by maximum weight loss of $60 \%$ observed from 250 to $350{ }^{\circ} \mathrm{C}$ due to a 244 progressive degradation of hemicellulose, cellulose, and lignin.

246 In contrast to pith, the PET exhibited maximum mass loss at a higher temperature of $400-575^{\circ} \mathrm{C}$, 247 where it levelled-off but continued its degradation up to $700{ }^{\circ} \mathrm{C}$. These results were similar to 248 previous studies on the co-pyrolysis of biomass and plastics (Li et al., 2013; Ratnasari et al., 2017). 249 It was anticipated that the mixture of biomass and PET would present different degradation 250 patterns. In addition, catalysts (e.g. zeolites) could change the thermal decomposition profile of 251 the mixed pith and PET, by influencing the interactions among volatile components released from 252 the materials during pyrolysis. The catalytic activity could be interrupted by the effect of biomass 253 decompositions products, by deactivating the acidic zeolite sites and delay the catalytic reactions 254 of the plastics (Zhang et al., 2012). Literature shows that co-pyrolysis of biomass and plastic 255 mixtures are carried out above the normal biomass pyrolysis temperature of $500{ }^{\circ} \mathrm{C}$ due to the 256 technical problem of the presence of heavy hydrocarbons in the resulting oil product. Hence, a 257 potential solution to this problem is to operate co-pyrolysis systems at temperatures of $700{ }^{\circ} \mathrm{C}$ and 258 above (Lin et al., 2015; Uzoejinwa et al., 2018). Therefore, based on results from TGA/DTG 259 studies and literature sources, it was decided to carry out the co-pyrolysis tests at $700{ }^{\circ} \mathrm{C}$, with the 260 validation of the optimised parameters in Section 3.6. 
263 The non-catalytic fast pyrolysis of pith and PET was first performed using the Py-GC-MS. Figs.

$2642 \mathrm{a}$ and $2 \mathrm{~b}$ present the chromatograms from the non-catalytic tests, illustrating the distribution of 265 products derived from separate components of pith and PET. Without the HZSM-5, the pith of 266 sugarcane bagasse decomposed into a distribution of different oxygenates as a result of the 267 breakdown of cellulose, hemicellulose, and lignin, while a mixture of hydrocarbons (alkenes and 268 alkanes) is liberated from the thermal decomposition of the long hydrocarbon chain structure of 269 PET. Anhydrosugars like levoglucosan, furans, alcohols, and ketones were the main products for 270 the non-catalytic pyrolysis of pith, similar to those reported elsewhere (Ghorbannezhad et al., $2712018 a, 2018 b)$.

273 3.4. Catalytic fast co-pyrolysis of PET and pith

274 As can be seen from the chromatograms in Fig. 2c, catalytic pyrolysis of pith over HZSM-5 275 predominantly decreased the content of oxygenated compounds and increased the yields 276 hydrocarbons. The compounds identified were similar to those reported in literature (Karagoz et 277 al, 2016; Ghorbannezhad et al, 2018) and included furan, benzene, toluene, xylenes, ethylbenzene, 278 indenes, and naphthalene, which were totally different from the products of non-catalytic fast 279 pyrolysis. Catalysts can therefore enable the change in type, yield, and distribution of products 280 during fast pyrolysis process.

282 While, it is worth noting that catalytic fast pyrolysis of biomass is a method to produce 283 deoxygenated pyrolysis liquids, it is still a low-efficiency process because catalytic mechanisms 284 lead to loss of hydrogen (mainly as water via dehydration) from the biomass, leading to 
285 condensation of carbon atoms to form coke and consequently causing catalyst deactivation, which

286 shortens catalyst life-time. The oxygenated compounds in bio-oil or pyrolysis vapours are known

287 to undergo severe thermal degradation on solid acid catalysts, resulting in the formation of

288 carbonaceous deposits on the catalyst, and consequently, lead to an intense deactivation of the

289 catalyst (Sebestyne, et al, 2017). Zhang et al. (2015) also reported that the higher catalyst

290 deactivation occurred at a lower $\mathrm{H} / \mathrm{C}_{\text {eff }}$ ratio of biomass feedstock which resulted in reduction of

291 aromatics yields. The loss of hydrogen can be compensated by mixing plastic as a hydrogen-

292 enriched reactant. HZSM-5 being a shape-selective acidic catalyst, can convert the anhydrosugars

293 into smaller molecules, such as furans, HMF, aldehydes, and other acids through carbocation

294 formation on the external surface acid sites of the catalyst (Speight, 1991). In addition, aromatic

295 formation has been reported to occur with Brønsted sites of HZSM-5 through a "hydrocarbon 296 pool", in which aromatic hydrocarbons formed inside the zeolite pores as a result of catalysed

297 conversion of oxygenated compounds (Dorado et al., 2015). Regarding the aromatization reaction

298 pathway, some studies generally have confirmed the following steps: a) cracking and

299 deoxygenation of biomass into small C2-C5 olefins; b) oligomerization of C2-C5 olefins to

300 C6-C10 olefins, followed by transformation to $\mathrm{C} 6-\mathrm{C} 10$ dienes by transfer reactions; c)

301 aromatization of the dienes (Mullen and Boateng, 2015; Hoff et al., 2016).

302

303 Hoff et al. (2016) revealed that aromatics formation was strongly dependent on the crystallinity 304 and accessibility of framework aluminum sites over zeolite-based catalysts. However, the same 305 mechanisms are responsible for rapid deactivation of zeolite catalyst from coke formation (Mullen 306 and Boateng, 2015). Therefore, to improve catalysts' lifetime and reduce the formation of coke, 307 the use of specific sodium-based catalytic additives can be an interesting option because this 
specific material offers large pores (microporous), giving better access for large and bulky molecules and thus enhancing the catalytic conversion to aromatics.

\subsection{Catalytic co-pyrolysis over sodium-based catalyst}

312 The chromatogram in Figure $2 \mathrm{~d}$ shows that the co-pyrolysis of biomass and PET over the 313 combined HZSM-5/ $\gamma-\mathrm{Na}_{2} \mathrm{CO}_{3}$ catalysts enhanced the selectivity of aromatic hydrocarbons in the 314 liquid product. Such a synergistic effect between PET and bagasse during the co-pyrolysis could 315 both improve the aromatics and reduce the coke formation (Dorado et al., 2015; Li et al., 2013; 316 2014). Hence to test this hypothesis, a quick set of experiments was carried out to evaluate the 317 effect of increasing PET/biomass ratio on coke formation in the absence of catalyst. The results 318 are shown in Supplementary Information Fig. SI1, indicating that coke formation reduced with 319 increasing PET in the plastic/biomass blend, indicating that the plastic could prevent coke 320 formation. The reduction of coke formation during catalytic co-pyrolysis of biomass and PET can 321 help to extend the HZSM-5 life-time and further enhance the yields of the desired products. This 322 will be the subject of future research.

324 Fig. 3 presents the total yields of the aromatic hydrocarbon products from the co-pyrolysis of pith 325 at $700{ }^{\circ} \mathrm{C}$ with PET using a biomass/PET ratio of 4 and an $\mathrm{HZSM}-5 / \gamma-\mathrm{Al}_{2} \mathrm{O}_{3} / \mathrm{Na}_{2} \mathrm{CO}_{3}$ of 5 . The 326 cumulative amount of carbon in the aromatic products was around $22 \%$. The transfer of hydrogen 327 from PET-derived aliphatics toward the lignin-derived oxygenated compounds could mitigate 328 polymerization and cross-linking char forming reactions. In fact, using PET as a hydrogen-rich 329 plastic appeared to support the 'hydrocarbon pool' pathway, ensuring that the oxygenated primary 330 pyrolysis products of biomass do not cause coke formation. Results also showed that $\mathrm{H}_{2} \mathrm{O}$ 
331 formation decreased, leading to an increase in aromatic compounds. The major aromatic 332 compounds obtained were ethylbenzene, toluene, and xylenes.

333 In addition to the 'hydrocarbon pool' pathway, aromatics formation during pyrolysis can occur via 334 the Diels-Alder cycloaddition of olefin gases (ethylene and propylene) and furan derivatives over 335 zeolite catalysts (Cheng and Huber, 2011). Hence, it is possible that the reactions between olefin 336 gases from PET and furans from pith, could have occurred in this study, leading to enhanced yields 337 of aromatic hydrocarbons such as benzene, toluene, and xylenes (Cheng et al., 2012). A plausible 338 schematic of aromatic hydrocarbon production via the combination of the hydrocarbon pool 339 pathway and the Diel-Alder reactions from the co-pyrolysis of biomass and plastic is illustrated in $340 \quad$ Fig. 4.

342 The catalysts seemed to have intensified the secondary reactions of organic components involving $343 \mathrm{C}-\mathrm{C}, \mathrm{C}-\mathrm{O}$, and $\mathrm{C}-\mathrm{H}$ bond cleavage during CFP. It would appear that the $\mathrm{Na}_{2} \mathrm{CO}_{3}$ improved the 344 deoxygenating rate and life-time of the zeolite catalysts by reducing surface coke formation, which 345 can be favourable towards the scale-up of the CFP process. Enhanced deoxygenation rate during 346 in-situ catalytic fast pyrolysis of Jatropha seed cake using $\mathrm{Na}_{2} \mathrm{CO}_{3}$ as catalyst has been reported 347 by Imran et al. (2016). In their study, the catalyst was mixed in a bench-scale entrained flow reactor 348 setup and resulted in an upgraded bio-oil with very low oxygen and water contents (7.1 and 6.8 349 wt.\%, respectively), due to removal of undesirable compounds, i.e., acids and aldehydes. 350 Consequently, there oil product showed a dramatic increase in the aliphatic and aromatic 351 hydrocarbons content (Imran et al., 2016). It has been also observed that the sodium-based 352 catalysts like $\mathrm{Na}_{2} \mathrm{CO}_{3} / \gamma-\mathrm{Al}_{2} \mathrm{O}_{3}$ were the most active for deoxygenation of pyrolysis products 353 (Nguyen et al., 2013). In this present work, the decrease in oxygen content was accompanied by a 
354 dramatic increase in $\mathrm{CO}_{2}$ production during the Py-GC-MS experiment (Fig. 2d). The selectivity

355 of oxygenated compounds toward $\mathrm{CO}_{2}$ is desirable in biomass deoxygenation to minimize 356 hydrogen loss. Nguyen et al. (2016) revealed that carboxylic acids were completely removed, and 357 hydrocarbon content significantly increased in the presence of the $\mathrm{Na}_{2} \mathrm{CO}_{3} / \gamma-\mathrm{Al}_{2} \mathrm{O}_{3}$ catalyst. 358 Nguyen et al. (2015) proposed the conversion of carboxylic acids over $\mathrm{Na}_{2} \mathrm{CO}_{3} / \gamma-\mathrm{Al}_{2} \mathrm{O}_{3}$ occurred 359 via the ketonisation of carboxylic acids, with subsequent decarboxylation/dehydration over 360 HZSM-5 into olefins. However, the catalyst was reported to have suffered from agglomeration and 361 loss of activity. However, chemical interaction or agglomeration of HZSM-5 and $\mathrm{Na}_{2} \mathrm{CO}_{3} / \gamma-\mathrm{Al}_{2} \mathrm{O}_{3}$ 362 catalysts have not been determined in this present study.

3.6 Optimization of catalytic co-pyrolysis process over sodium-based HZSM5 catalyst mixture

365 As shown in Fig. 5, the independent effect of the HZSM-5 to $\mathrm{Na}_{2} \mathrm{CO}_{3} / \gamma-\mathrm{Al}_{2} \mathrm{O}_{3}$ ratio was 366 investigated to achieve preliminary optimisation of valuable co-pyrolysis products (aromatics, 367 BTXE, olefins, and phenols). The effect of the HZSM-5 addition was established within the range 368 of a 1 to 5 ratio relative to pith (biomass) in this study. The effect of changing the HZSM-5/ $369 \mathrm{Na}_{2} \mathrm{CO}_{3} / \gamma-\mathrm{Al}_{2} \mathrm{O}_{3}$ ratio was more pronounced in the yields of phenols compared to BTXE. An HZSM-5 to the $\gamma-\mathrm{Na}_{2} \mathrm{CO}_{3}$ ratio of 4 gave the highest phenols yield as shown in Fig. 5.

373 In comparison with the effects of the HZSM-5 to $\mathrm{Na}_{2} \mathrm{CO}_{3} / \gamma-\mathrm{Al}_{2} \mathrm{O}_{3}$ ratio, the biomass to PET ratio 374 showed a greater effect on the yield of valuable co-pyrolysis products (Fig. 6). For instance, the 375 BTXE yield increased by increasing the biomass to PET ratio, while an increase in HZSM-5 to $376 \mathrm{Na}_{2} \mathrm{CO}_{3} / \gamma-\mathrm{Al}_{2} \mathrm{O}_{3}$ did not show significant effects. The optimal biomass to PET was determined at 377 a ratio of 4 when the maximum aromatics, BTXE, olefins, and phenols were obtained at carbon 
378 yields of around 22\%, 19\%, 17\%, and 7\%, respectively (Fig. 6). The independent effect of biomass

379 to PET revealed that the phenols also exhibited the most significant changes in co-pyrolysis

380 valuable products, relative to changes in BTXE and aromatics. However, the total yields of phenols

381 were much lower compared to BTXE.

382

383 Fig. 7 shows the aromatics and BTX efficiency by evaluating several parameters such as biomass to PET ratio, $\mathrm{HZSM}-5$ to $\mathrm{Na}_{2} \mathrm{CO}_{3} / \gamma-\mathrm{Al}_{2} \mathrm{O}_{3}$, and temperature on the co-pyrolysis process. It can be ascertained from Fig. 7 that the combination of $\mathrm{HZSM}-5$ and $\mathrm{Na}_{2} \mathrm{CO}_{3} / \gamma-\mathrm{Al}_{2} \mathrm{O}_{3}$ catalyst was the most effective parameter, resulting in $18 \%$ oxygen removal and $19 \%$ of BTX yields than either HZSM-5 or $\mathrm{Na}_{2} \mathrm{CO}_{3} / \gamma-\mathrm{Al}_{2} \mathrm{O}_{3}$ alone. This could be attributed to the enhanced co-pyrolysis process due to more deoxygenation and formation of aromatic as well as reduction of coke. Ghorbannezhad et al. (2018b) indicated that the highest BTX compounds were obtained when using HZSM-5 with a $\mathrm{Si} / \mathrm{Al}$ ratio of 23 . They reported that the increased cracking reaction of the primary pyrolysis products taking place on the HZSM-5 zeolite catalyst could be attributed to the acidic nature of HZSM-5.

Zhang et al. (2016) reviewed the co-pyrolysis performance which can be influenced by process parameters like temperature, type of catalysts, and the ratio of co-reactants on the liquid products. 395 Nguyn et al. (2015) proposed that the coordination of $\mathrm{Na}^{+}$ions and the hydroxyl and alkoxyl groups on the surface of $\mathrm{Na}_{2} \mathrm{CO}_{3} / \gamma-\mathrm{Al}_{2} \mathrm{O}_{3}$ was responsible for improving deoxygenation which 397 corresponded to higher number of sodium active sites. On the other hand, the pivotal role of sodium concentrations rather than the surface area of catalysts resulted in the lignin-derived compounds being promoted through catalytic scission of these groups over $\mathrm{Na}_{2} \mathrm{CO}_{3} / \gamma-\mathrm{Al}_{2} \mathrm{O}_{3}$ catalyst. 
401 Based on the statistical analysis, the full quadratic model was selected as the best model and

402 biomass to PET ratio was shown to have the most significant effect on the aromatic compounds

403 yields and coke formation. The optimal yields of BTXE (18.3\%) and total aromatic compounds

$404(20.3 \%)$ were obtained at a temperature of $700{ }^{\circ} \mathrm{C}$, biomass to PET ratio of 4, and HZSM-5 to

$405 \mathrm{Na}_{2} \mathrm{CO}_{3} / \gamma-\mathrm{Al}_{2} \mathrm{O}_{3}$ ratio of 5 . To validate the optimisation results, additional experiments with three

406 replications were carried out at the optimum situation. It was observed that the BTXE yield (18.3\%

$407 \pm 1.04)$, aromatics $(20.3 \% \pm 0.79)$, olefins $(17 \% \pm 0.65)$ and phenols $(7 \% \pm 0.23)$ were close to the

408 predicted values $(\mathrm{P}<0.05)$, which indicated the high accuracy of the presented models.

409

\section{4. Conclusions}

411 This study has revealed that the co-pyrolysis of sugarcane bagasse pith with PET, using an ex-situ

412 Py-GC-MS, increased the production of aromatic compounds, especially BTXE and minimized

413 the formation of coke. Results indicated that the PET strongly influenced the thermal

414 decomposition of lignin in pith during the co-pyrolysis study. This implied that the transfer of

415 hydrogen from PET-derived aliphatics toward the lignin-derived oxygenated compounds could

416 mitigate polymerisation and cross-linking char forming reactions. In addition, dehydration

417 reactions that generate $\mathrm{H}_{2} \mathrm{O}$ are suppressed. Moreover, the combination of sodium-based catalyst

$418\left(\mathrm{Na}_{2} \mathrm{CO}_{3} / \gamma-\mathrm{Al}_{2} \mathrm{O}_{3}\right)$ with HZSM-5 improved the deoxygenation reactions, while reducing coke

419 formation. Optimisation of ex-situ co-pyrolysis indicated that the maximum yields of aromatic

420 compounds were obtained at $700{ }^{\circ} \mathrm{C}$, biomass to PET ratio of 4 , and HZSM-5 to $\mathrm{Na}_{2} \mathrm{CO}_{3} / \gamma-\mathrm{Al}_{2} \mathrm{O}_{3}$

421 ratio of 5. At these conditions, an optimum BTX yield of $18.3 \%$ was obtained. Finally, this present

422 study showed that catalytic fast pyrolysis technology can be deployed to reduce the disposal of 
waste plastics in landfills, reduce our dependence of fossil fuels, and introduced new pyrolysisbased biorefinery pathways in chemical industries.

\section{Acknowledgments}

This study was supported partially by the ENgineering and TEchnology Institute Groningen (ENTEG) and Department of Chemical Engineering (award number: 190138720) and Department of Biorefinery Engineering at Shahid Beheshti University, Iran (award number: 397081).

\section{References}

ASTM D5373-16, 2016. Standard Test Methods for Determination of Carbon, Hydrogen, and Nitrogen in Analysis Samples of Coal and Carbon in Analysis Samples of Coal and Coke, ASTM International, West Conshohocken, PA.

Bridgwater, A.V., 2012. Review of fast pyrolysis of biomass and product upgrading. Biomass Bioenerg. 38, 68-94.

Brebu, M., Ucar, S., Vasile, C., Yanik, J. 2010. Co-pyrolysis of pine cone with synthetic polymers. Fuel 89, 1911-1918.

Caglar, A., Aydinli, B. J. 2009. Isothermal co-pyrolysis of hazelnut shell and ultra-high molecular weight polyethylene: The effect of temperature and composition on the amount of pyrolysis products, J. Anal. Appl. Pyrolysis 86, 304-309.

Carlson, T.R, Vispute, T. P. and Huber, G. W. 2008. Green gasoline by catalytic fast pyrolysis of solid biomass-derived compounds. ChemSusChem 1 (5), 397-400.

Carlson, T. R, Cheng, Y.-T., Jae, J. Huber, G. W. 2011. Production of Green Aromatics and Olefins by Catalytic Fast Pyrolysis of Wood Sawdust, Energ. Environ. Sci. 4, 145-161.

Chambon, C.L., Mkhize, T.Y., Reddy, P., Brandt-Talbot, A., Deenadayalu, N., Fennell, P.S. and Hallett, J.P., 2018. Pretreatment of South African sugarcane bagasse using a low-cost protic ionic liquid: a comparison of whole, depithed, fibrous and pith bagasse fractions. Biotechnol. Biofuels 11, 247-262. 
Chattopadhyay, J., Pathak, T.S., Srivastava, R., Singh, A.C. 2018. Catalytic co-pyrolysis of paper biomass and plastics mixtures, HDPE, PP and PET, and product analysis. Energy 103, 513-521.

Cheng, Y.-T., Huber, G. W. 2011. Chemistry of Furan Conversion into Aromatics and Olefins over HZSM-5: A Model Biomass Conversion Reaction. ACS Catal. 1(6), 611-628.

Cheng, Y. T., Jae, J., Shi, J., Fan, W., Huber, G. W., 2012. Renewable Aromatics Production by Catalytic Fast Pyrolysis of Lignocellulosic Biomass with Bifunctional Ga/ZSM-5 Catalysts. Angew. Chem. Int. Edit. 51, 1387-1390.

Diaz-Silvarrey, L., McMahan, A., Phen, A.N. 2018. Benzoic acid recovery via waste poly (ethylene terephthalate) (PET) catalytic pyrolysis using a solphated zirconia catalyst. J. Anal. Appl. Pyrol. 134, 621-631.

Dorado, C., Mullen, C. A., Boateng, A. A. 2015. Origin of carbon in aromatic and olefin products derived from HZSM-5 catalyzed co-pyrolysis of cellulose and plastics via isotopic labeling. Appl. Catal. B- Environ. 162, 338-345.

Dorado, C., Mullen, C. A., Boateng, A. A. 2014. H-ZSM5 catalyzed the co-pyrolysis of biomass and plastics. ACS Sustain. Chem. Eng. 2, 301-311.

Elkasabia, Y., Mullen, C.A., Pighinelli, A.L.M.T., Boateng, A.A., 2014. Hydrodeoxygenation of fast-pyrolysis bio-oils from various feedstocks using carbon-supported catalysts. Fuel Proc.

Technol. 123, 11-18

FAOSTAT, 2018. Statistic Report, crops, http://www.fao.org/faostat/en/\#data/QC/visualize. Accessed November 10, 2018.

Ghorbannezhad, P., Dehghani, M.R., Ghasemian, A., Wild, P., Heeres, J.H. 2018. Sugarcane bagasse ex-situ catalytic fast pyrolysis for the production of Benzene, Toluene, and Xylenes (BTX), J. Anal. Appl. Pyrol, 131, 1-8.

Ghorbannezhad, P., Dehghani, M.R., Ghasemian, A. 2018. Catalytic fast pyrolysis of sugarcane bagasse pith with HZSM-5 catalyst using tandem micro-reactor-GC-MS. Energy. Source. Part A 40(1), 15-21.

Ghorbannezhad, P., Bay, A., Youlmeh, M., Yadollahi, R., Moghadam, Y.J., 2016. Optimization of coagulation-flocculation process for medium density fiberboard (MDF) wastewater through response surface methodology. Desalin. Water Treat. 1-16.

Heikkienen, J.M., Hordijk, J., de Jong, W., Spliethoff, H. 2004. Thermogravimetry as a tool to classify waste components to be used for energy generation. J. Anal. Appl. Pyrol. 71, 883-900. 
Hoff, T., Gardner, D.W., Thilakaratne, R., Wang, K., Hansen, T.W., Brwon, R.C., Tessonnier, J.P. 2016. Tailoring ZSM-5 zeolites for the fast pyrolysis of biomass to aromatic hydrocarbons. ChemSusChem 9, 1473-1482.

Imran, A., Bramer, E.A., Seshan, K., Brem, G., 2016. Catalytic flash pyrolysis of oil impregnatedwood and jatropha cake using sodium-based catalysts. J. Anal. Appl. Pyrolysis. 117, 236-246.

Jin, Q., Wang, X., Li, S., Mikulicic, H., Besenic, T., Deng, S., Vujanovic, M., Tan, H., Kumfer, B. 2017. Synergic effects during co-pyrolysis of biomass and plastics: Gas, Tar, Soot, Char products, and thermogravimetric study. J. Energy. Inst, https://doi.org/10.1016/j.joei.2017.11.001

Karagoz, S., Kawakami, T., Kako, A., Liguni, Y., Ohtani, H. 2016. Single shot pyrolysis and online conversion of lignocellulosic biomass with HZSM-5 catalyst using tandem-micro-reactorGC-MS, RSC advances, 6, 46108-46115.

Ko, K.H., Sahajwalla, V., Rawal, A. 2014. Specific molecular structure changes and radical evolution during biomass-polyethylene terephthalate co-pyrolysis detected by (13)C and (1)H solid-state NMR. Biores. Technol. 170, 248-255.

Li, J., Yu, Y., Li, X., Wang, W., Yu. G., Deng, S., Huang, J., Wang, B., Wang, Y., 2015. Maximizing carbon efficiency of petrochemical production from catalytic co-pyrolysis of biomass and plastics using gallium-containing MFI zeolites. Appl. Catal. B: Environ. 172-173, 154-164.

Li, X.; Li, J.; Zhou, G.; Feng, Y.; Wang, Y.; Yu, G.; Deng, S.; Huang, J.; Wang, B. 2014. Enhancing the production of renewable petrochemicals by co-feeding of biomass with plastics in catalytic fast pyrolysis with ZSM-5 zeolites. Appl. Catal. A: General 481, 173-182.

Li, X.; Zhang, H.; Li, J.; Su, L.; Zuo, J.; Komarneni, S.; Wang, Y. 2013. Improving the aromatic production in catalytic fast pyrolysis of cellulose by co-feeding low-density polyethylene. Appl. Catal. A: General 455, 114-121.

Lin, X., Zhang, Z., Sun, J., Guo, W, Wang, Q., 2015. Effects of phosphorus-modified HZSM-5 on distribution of hydrocarbon compounds from wood-plastic composite pyrolysis using PyGC/MS. J. Anal. Appl. Pyrol. 116, 223 -230.

Lu, P., Hung, Q., Bourtsalas, A.C., Chi, Y., Yan, J. 2018. Synergistic effect on char oil produced by the co-pyrolysis of pinewood, polyethylene, and polyvinyl chloride. Fuel 230, 359-367.

Marin, N.; Collura, S.; Sharypov, V. I.; Beregovtsova, N. G.; Baryshnikov, S. V.; Kutnetzov, B. N.; Cebolla, V. L.; Weber, J. V. 2002. Co-pyrolysis of wood biomass and synthetic polymers mixtures. Part II: characterization of the liquid phases. J. Anal. Appl. Pyrol. 65 (1), 41-55.

Myers, R.H., Montgomery, D.C., Anderson-Cook, C.M., 2011. Response Surface Methodology: Process and product optimization using designed experiments. John Wiley \& Sons, New York, NY, (3rd Edition). 
Mullen, C.A., Boateng, A.A. 2015. Production of aromatic hydrocarbons via catalytic pyrolysis of biomass over Fe-Modified HZSM-5 zeolites. ACS Sustain. Chem. Eng. 3, 1623-1631.

Nguyen, T.S., He, S, Raman, G., Seshan, K. 2016. Catalytic hydro-pyrolysis of lignocellulosic biomass over dual $\mathrm{Na}_{2} \mathrm{CO}_{3} / \mathrm{Al}_{2} \mathrm{O}_{3}$ and $\mathrm{Pt} / \mathrm{Al}_{2} \mathrm{O}_{3}$ catalysts using n-butane at ambient pressure. Chem. Eng. J. 299, 415-419.

Nguyen, T.S., Lefferts, L., Gupta, S.K., Seshan, K. 2015. Catalytic conversion of biomass pyrolysis vapors over sodium-based catalyst: A study on the state of sodium on the catalyst. ChemCatChem 7, 1833 - 1840.

Nguyen, T.S, Zabeti, M., Lefferts, L, Brem, G, Seshan, K. 2013. Catalytic upgrading of biomass pyrolysis vapours using faujasite zeolite catalysts. Biomass Bioenerg. 48, 100-110.

Pinto, F., Miranda, M., Costa, P. 2016. Production of liquid hydrocarbons from rice crop wastes mixtures by co-pyrolysis and co-hydropyrolysis. Fuel 174 (15), 153-163.

Ratnasari, D. K., Nahil, M. A., Williams, P. T. 2017. Catalytic pyrolysis of waste plastics using staged catalysis for the production of gasoline range hydrocarbon oils. J. Anal. Appl. Pyrol. 124, 631-637.

Rainey, T. J., and Covey, G., 2016. Pulp and paper production from sugarcane bagasse. In O'Hara, I. M. and Sagadevan, M. (Eds.) Sugarcane-based Biofuels and Bioproducts. John Wiley \& Sons Inc, Hoboken, New Jersey, 259-280.

Sharypov, V. I., Marin, N., Beregovtsova, N. G., Baryshnikov, S.V., Kuznetsov, B. N., Cebolla, V. L., Weber, J. V. 2002. Co-pyrolysis of wood biomass and synthetic polymer mixtures. Part I: influence of experimental conditions on the evolution of solids, liquids, and gases. J. Anal. Appl. Pyrol. 64, 15-28.

Sebestyen, Z., Barta-Rajna, E., Bozi, J., Blazso, M., Jakab, E., Miskolezi, N., Soja, J., Czegeny, Zs. 2017. Thermo-catalytic pyrolysis of biomass and plastic mixtures using HZSM-5, Applied Energy, 207, 114-122.

Speight, J. G., 1991. Refining Chemistry. In The Chemistry and Technology of Petroleum, 2nd ed., revised and expanded; Heinemann, H., Ed.; Chemical Industries Series; Marcel Dekker, Inc., New York, 44, 473-497.

TAPPI, 2018. TAPPI Standards: Regulations and Style Guidelines. Norcross, GA 30024, USA

T.C.P.I.E. Office, 2017. Progress of the World's Plastics Industry in 2014-2015, China Plastics Industry, 44, 46

Teng, H. and Wei, Y.C., 1998. Thermogravimetric studies on the kinetics of rice hull pyrolysis and the influence of water pretreatment. Ind. Eng. Chem. Res. 37(10), 3806-3811. 
622

623

624

625

626

627

628

629

630

631

632

633

634

635

The Business Research Company, 2018. Aromatics Global Market Briefing 2018. Accessed July $\underline{31,2019 .}$.

Uzoejinwa, B.B., He, X., Wang, S., Abomohra, A. E-F., Hu, Y., Wang, Q., 2018. Co-pyrolysis of biomass and waste plastics as a thermochemical conversion technology for high-grade biofuel production: Recent progress and future directions elsewhere worldwide. Energy Con. Mgt, 163, 468-492

Vanderbosch, R.H., Prins, W. 2010. Fast pyrolysis technology development. Biofuel. Bioprod. Bior. 4(2), 178-208.

Wang, Y., He, T., Liu, K., Wu, J., Fang, Y., 2012. From biomass to advanced bio-fuel by catalytic pyrolysis/hydro-processing: Hydrodeoxygenation of bio-oil derived from biomass catalytic pyrolysis. Biores. Technol. 108, 280-284

Wang, K., Zhang, J., Shanks, B.H., Brown, R.C. 2015. Catalytic conversion of carbohydratederived oxygenates over HZSM-5 in a tandem micro-reactor system, Green Chem. 17, 557-564.

Wang, K., Kim, K. H, Brown, R. C. 2014. Catalytic pyrolysis of individual components of lignocellulosic biomass. Green Chem. 16, 727-735.

Wang, L., Lei, H., Lee, J., Chen, S., Tang, J., Ahring, B. 2013. Aromatic hydrocarbons from packed-bed catalysis coupled with microwave pyrolysis of Douglas fir sawdust pellets. RSC Advances 34 (3), 14609-14615.

Xue, Y., Braden, J. and Bai, X., 2017. Effect of Pretreatment on biomass pyrolysis for better quality of bio-oil. Proceedings of the AIChE Annual Meeting, October 2017. Indianapolis, USA.

Yao, W., Li, J., Feng, Y., Wang, W., Zhang, X., Chen, Q., Komarneni, S., Wang, Y. 2015. Thermally stable phosphorus and nickel modified ZSM-5 zeolites for catalytic co-pyrolysis of biomass and plastics. RSC Advances 5, 30485-30494.

Zhang, X., Lei, H., Chen, S., and Wu, J., 2016. Catalytic co-pyrolysis of lignocellulosic biomass with polymers: a critical review. Green Chem. 18, 4145-4169

Zhang, B., Zhong, Z., Ding, K., Song, Z. 2015. Production of aromatic hydrocarbons from catalytic co-pyrolysis of biomass and high-density polyethylene: Analytical Py-GC/MS study. Fuel 139, 622-628.

Zhang, H., Carlson, T. R., Xiao, R., Huber, G. W. 2012. Catalytic fast pyrolysis of wood and alcohol mixtures in a fluidized bed reactor. Green Chem. 14, 98-110.

Zhou, L.; Wang, Y.; Huang, Q.; Cai, J. 2006. Thermogravimetric characteristics and kinetic of plastic and biomass blends co-pyrolysis, Fuel. Process. Technol. 87 (11), 963-969. 

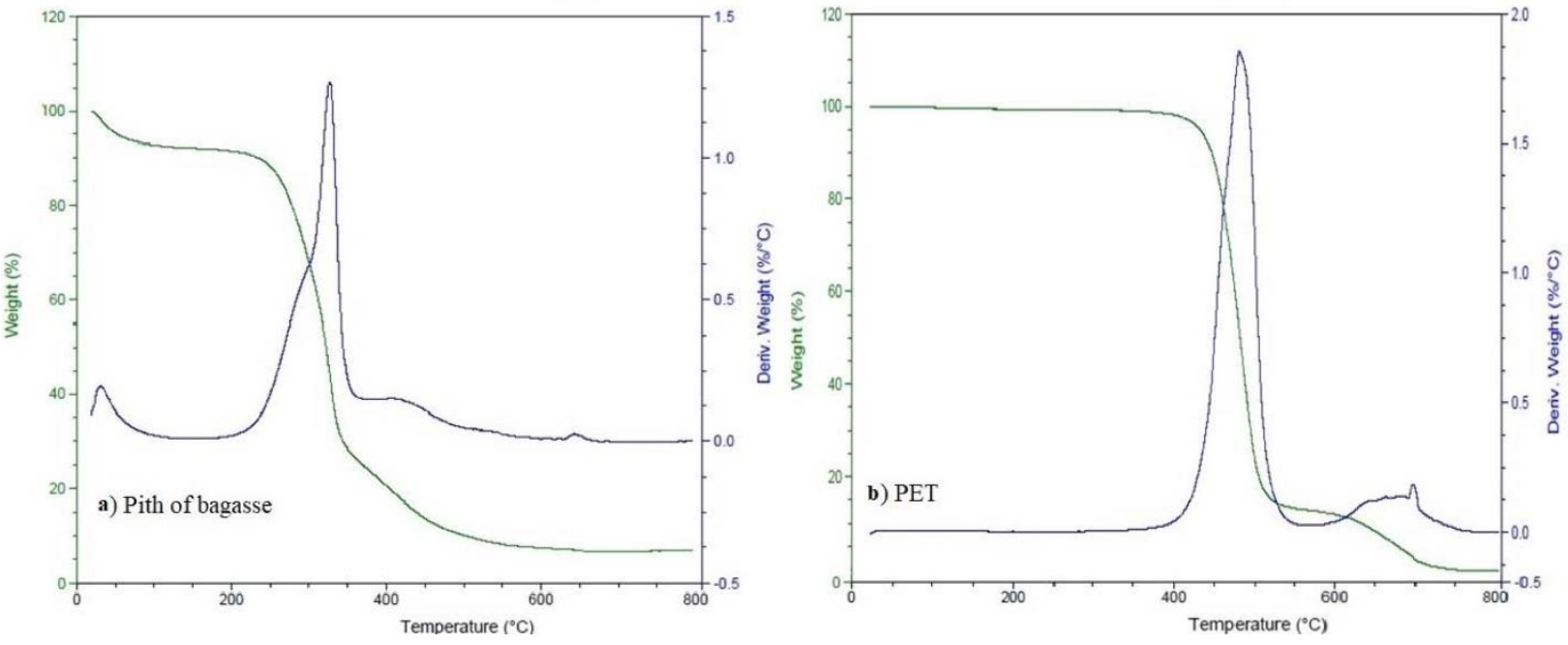

Fig. 1. TGA and DTG analysis, a) Pith of bagasse and b) PET 

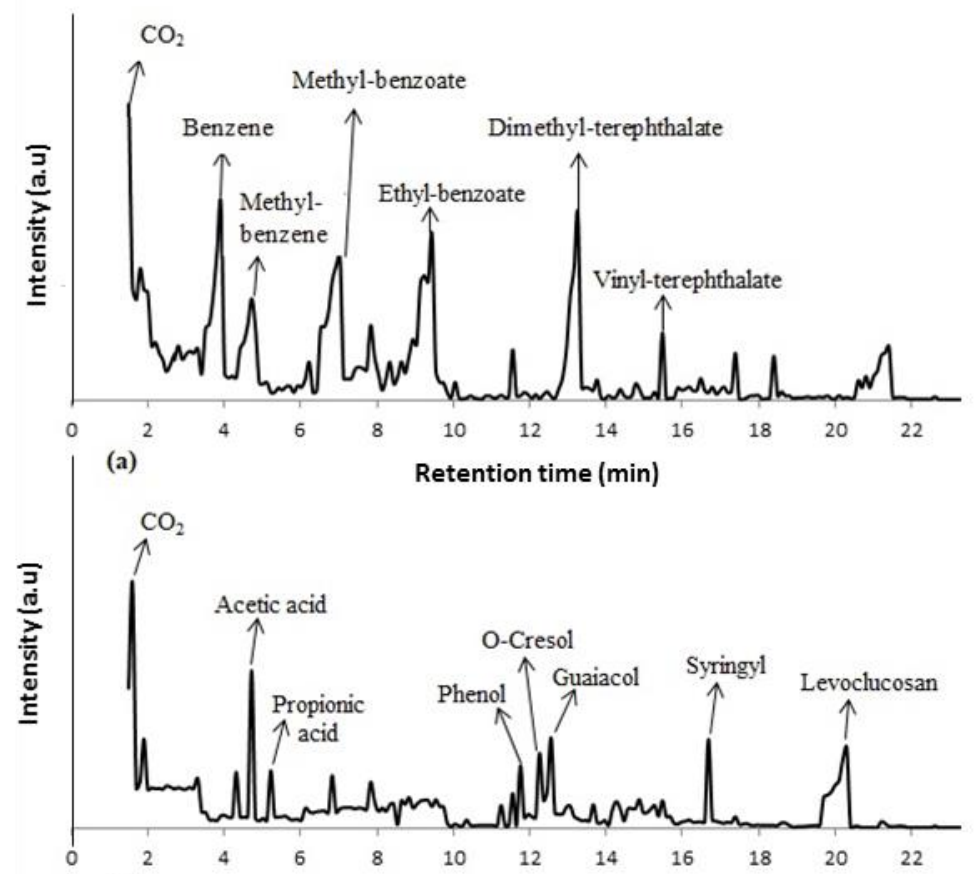

(b)

Retention time $(\mathrm{min})$

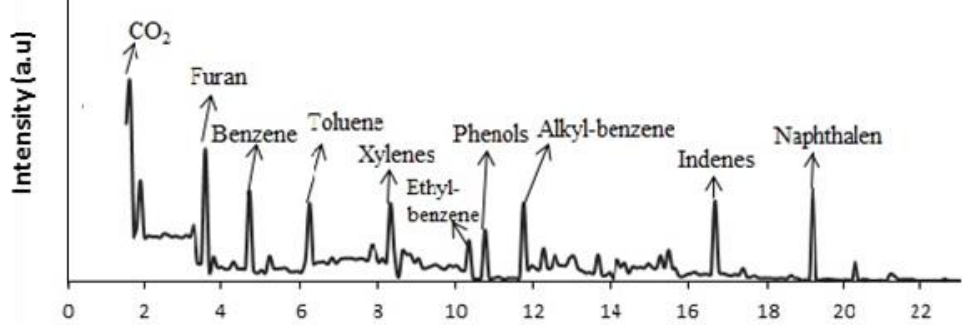

(c)

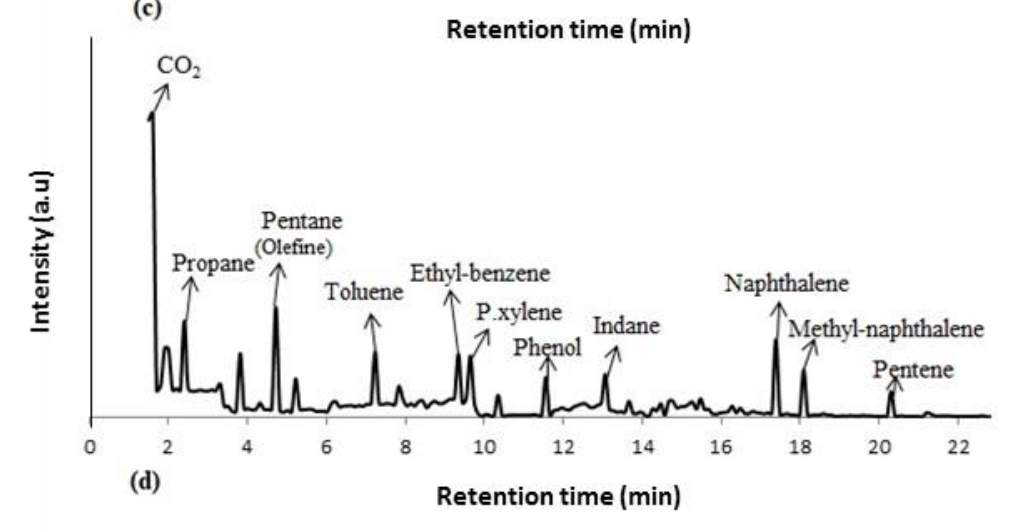

641

642 Fig. 2. Py-GC-MS chromatography for, a) PET; b) pith of bagasse; c) Pith of bagasse with

643 HZSM-5 catalyst; d) Co-pyrolysis of pith of bagasse with PET over HZSM-5 $/ \gamma-\mathrm{Na}_{2} \mathrm{CO}_{3}$ catalyst 


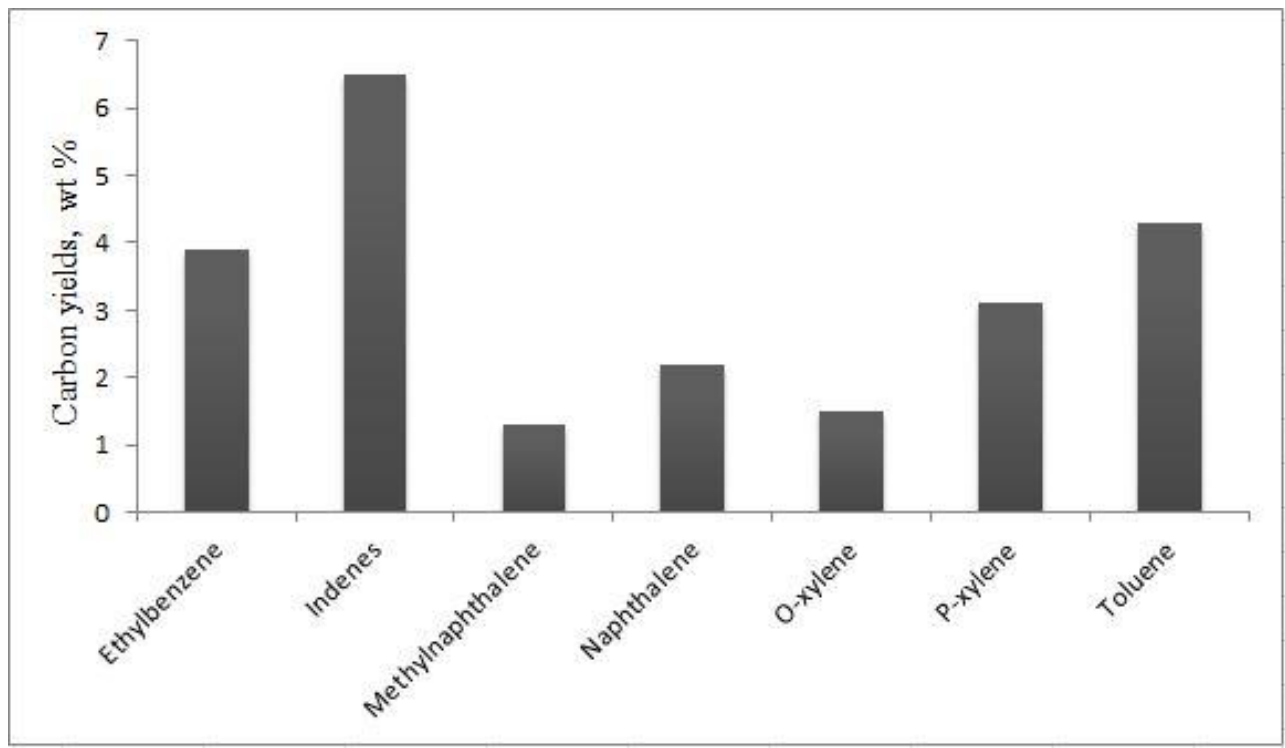

645 Fig. 3. Carbon yields of the aromatic hydrocarbons from co-pyrolysis in the presence HZSM-

$6465 / \gamma-\mathrm{Al}_{2} \mathrm{O}_{3} / \mathrm{Na}_{2} \mathrm{CO}_{3}$ at $700{ }^{\circ} \mathrm{C}$

647

648

649

650

651

652

653

654

655

656

657

658

659

660 


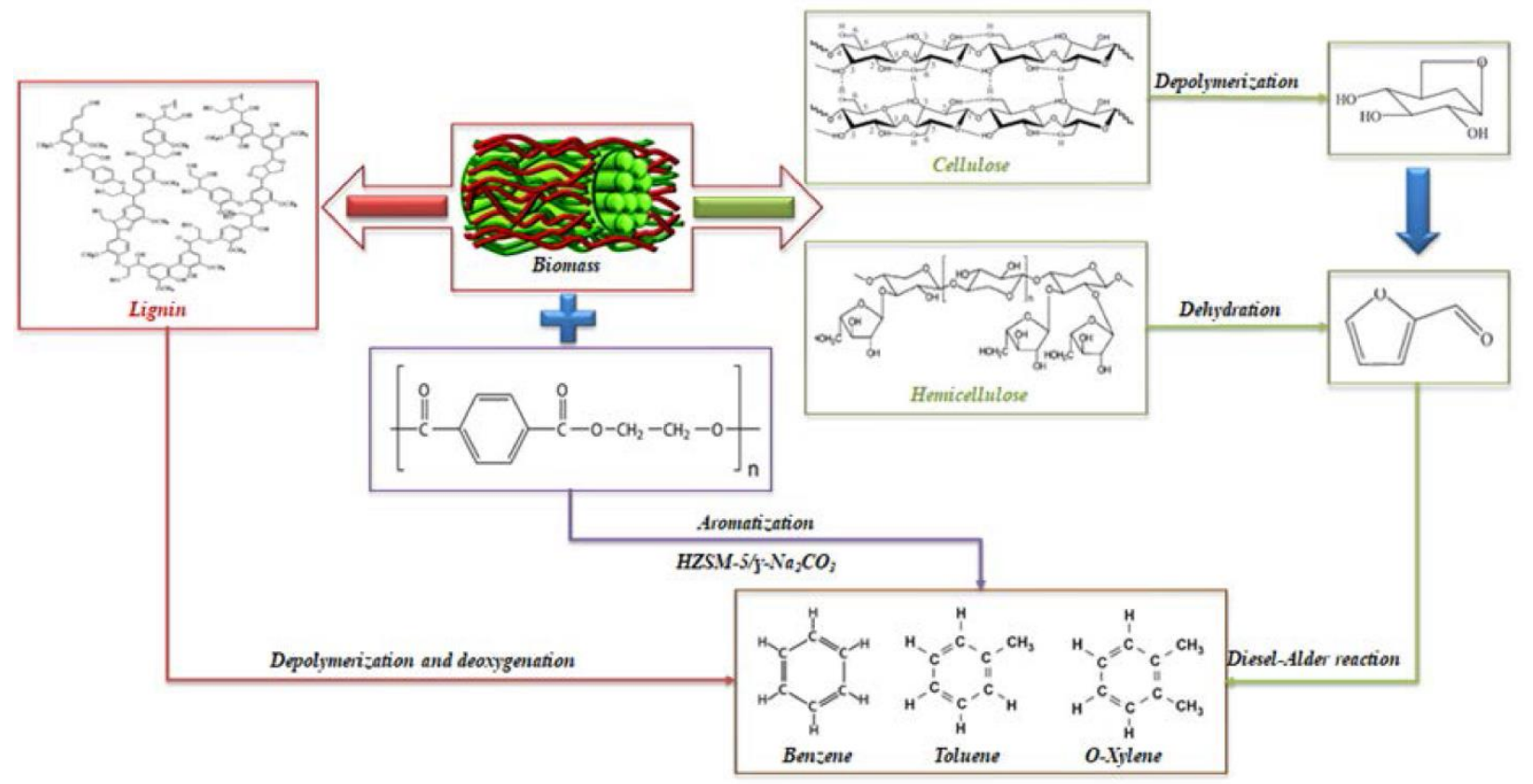

662

Fig. 4. The co-pyrolysis reaction pathways of biomass and PET

663

664

665

666

667

668

669

670

671

672

673

674

675

676 


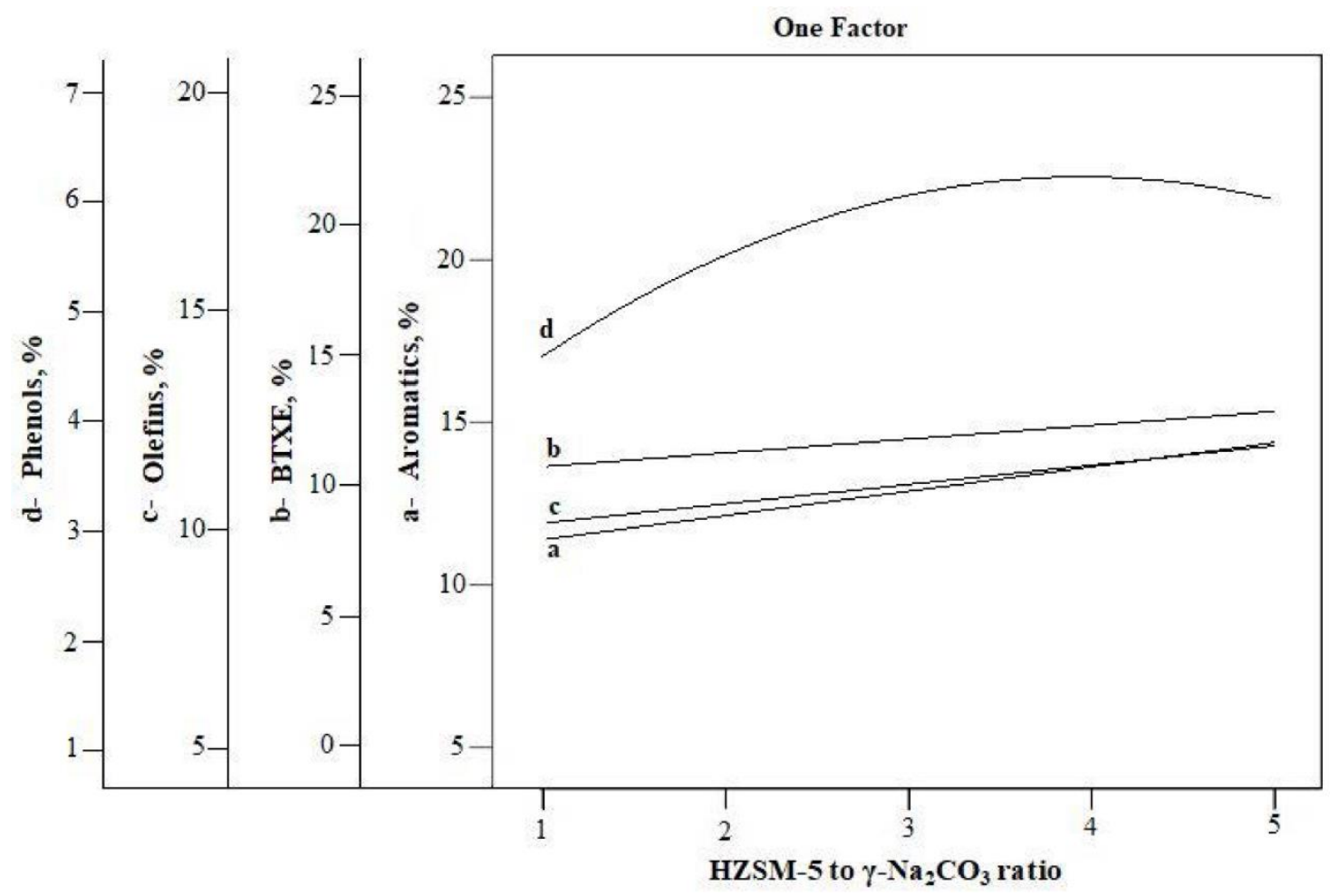

678 Fig. 5. The independent effect of HZSM-5 to $\gamma-\mathrm{Na}_{2} \mathrm{CO}_{3}$ on, a) Aromatics; b) BTXE; c) Olefins; 679 d) Phenols

680

681

682

683

684

685

686

687

688

689

690

691

692 


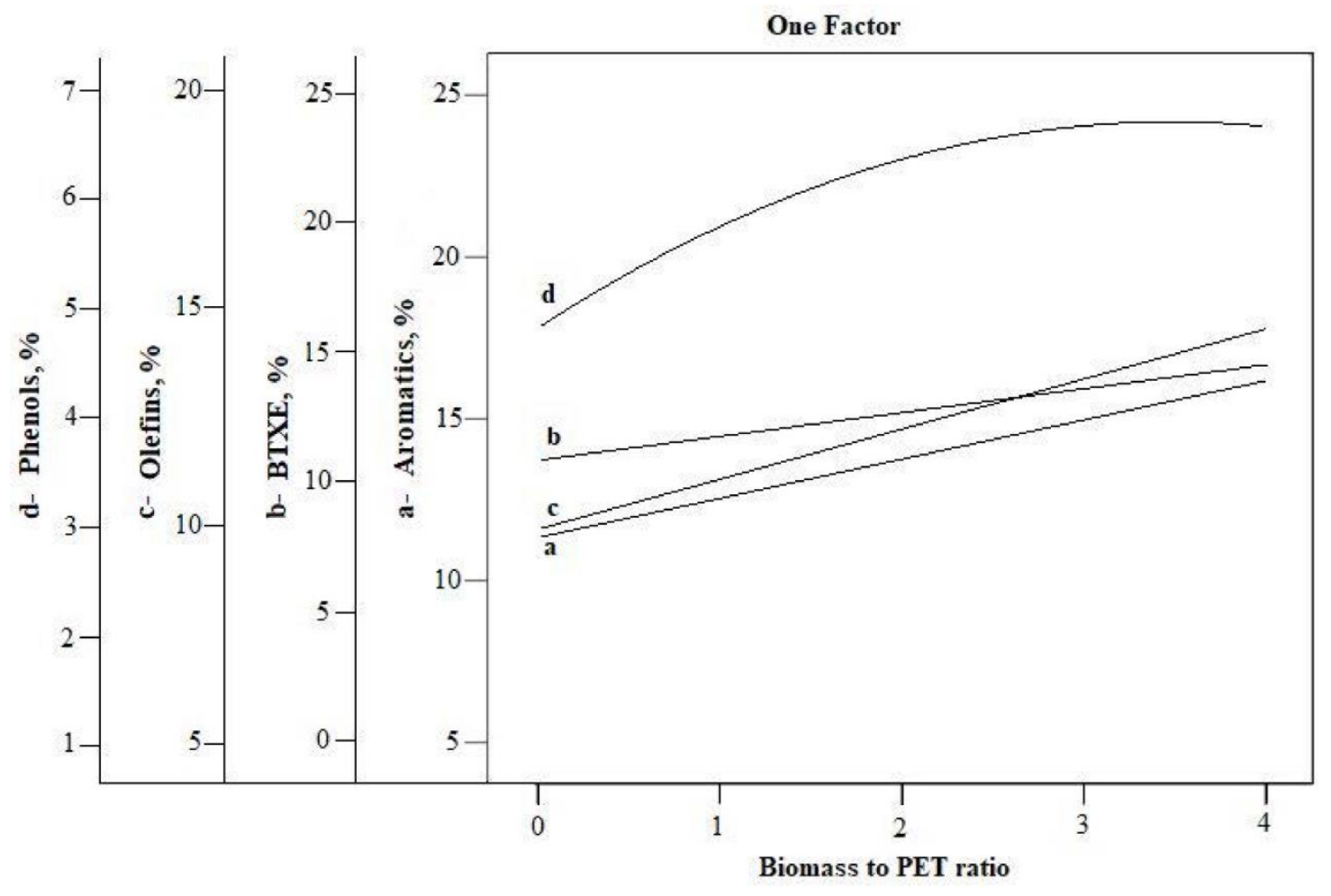

694 Fig. 6. The independent effect of Biomass to PET ratio on, a) Aromatics; b) BTXE; c) Olefins; 695 d) Phenols.

696

697

698

699

700

701

702

703

704

705

706

707

708 

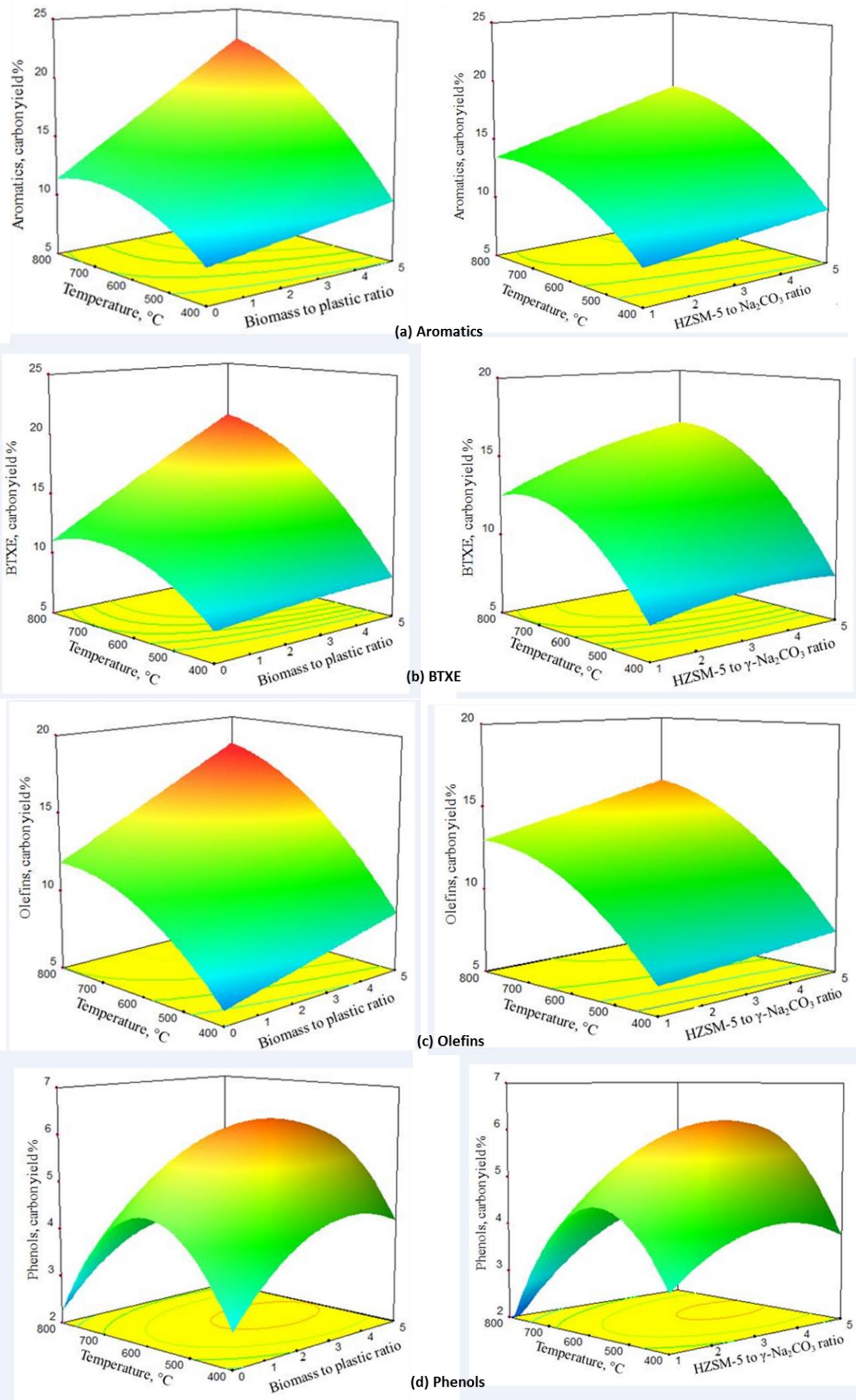

710 Fig. 7. The interaction between temperature, biomass to plastic ratio and HZSM-5 to $\gamma-\mathrm{Na}_{2} \mathrm{CO}_{3}$ on 711 the co-pyrolysis distributions, a) Aromatics; b) BTXE; c) Olefins; d) Phenols 